\title{
Cerebral infarction associated with benign mucin-producing adenomyosis: report of two cases
}

\author{
Koki Okazaki (D), Fumiaki Oka, Hideyuki Ishihara and Michiyasu Suzuki
}

\begin{abstract}
Background: Cerebral infarction associated with a malignant tumor is widely recognized as Trousseau syndrome. In contrast, few cases of cerebral infarction associated with benign tumors have been reported. We present two cases of embolic stroke that seemed to be caused by mucin-producing adenomyosis.

Case presentation: The patients were women aged 42 and 50 years old. Both patients developed right hemiparesis and aphasia, and cerebral infarctions were detected in the left cerebral hemisphere. There were no other abnormal findings, except for elevation of CA125 and D-dimer. Trousseau syndrome was suspected in both cases, but whole body examinations did not reveal any malignant tumors. However, uterine adenomyosis was detected in both patients.

Conclusions: From our findings and a review of the literature, both mucin-producing malignant tumors and mucinproducing benign tumors such as adenomyosis may cause hypercoagulability and cerebral infarction. This mechanism should be considered in a case of a young to middle-aged woman with embolic stroke of an undetermined origin.
\end{abstract}

Keywords: Cerebral infarction, Adenomyosis, Trousseau's syndrome, Benign tumor, Case report

\section{Background}

Mucin-producing malignant tumors may cause hypercoagulability and associated cerebral infarction that is widely referred to as Trousseau syndrome. Adenomyosis is also reported to produce mucin and to cause hypercoagulability [1, 2]. Here, we present two cases of embolic stroke that developed in middle-aged women and seemed to be caused by benign mucin-producing adenomyosis.

\section{Case presentation}

Patient 1 (Fig. 1): A 42-year-old woman with no medical history of note presented with right hemiparesis and aphasia, and was admitted to our hospital. The actual onset time was unknown. On arrival, her National Institutes of Health Score Scale (NIHSS) was 20. Diffusion-weighted brain magnetic resonance imaging (MRI) showed a hyperintense signal in the left middle cerebral artery (MCA) territory, and MR angiography (MRA) indicated occlusion of

\footnotetext{
* Correspondence: kouki818@yamaguchi-u.ac.jp

Department of Neurosurgery, Yamaguchi University School of Medicine,

1-1-1 Minami-Kogushi, Ube, Yamaguchi 755-8505, Japan
}

the left superior M2 (Fig. 1a, b). Because the infarct area seemed to match with the occluded artery territory, reperfusion therapy was not performed. After admission, we performed examinations to investigate the cause of cerebral infarction. Transthoracic echocardiography (TTE) and transesophageal echocardiography (TEE) showed no remarkable findings. A 24-h Holter electrocardiogram (ECG) did not show atrial fibrillation or other arrhythmia. Carotid echography and carotid MRA did not show atherosclerotic changes at proximal arteries. Blood tests were conducted to investigate the possibility of coagulation disorders, such as antiphospholipid antibody syndrome, collagen disease, protein $\mathrm{S}$ and $\mathrm{C}$ deficiency, antithrombin III deficiency, and tumor markers. However, the results were unremarkable, except for elevation of D-dimer $(1.4 \mu \mathrm{g} / \mathrm{mL})$ and CA 125 (395 U/mL; normal, <35 U/mL). Whole body enhanced computed tomography (CT) revealed no malignancy. Pelvic MRI showed uterine adenomyosis (Fig. 1c).

Patient 2 (Fig. 2): A 50-year-old woman with no medical history of note presented with right hemiparesis and mixed aphasia, and was admitted to a local hospital. The onset time was unknown. Diffusion-weighted imaging (DWI) in brain MRI revealed a hyperintense area in the

(c) The Author(s). 2018 Open Access This article is distributed under the terms of the Creative Commons Attribution 4.0 International License (http://creativecommons.org/licenses/by/4.0/), which permits unrestricted use, distribution, and 

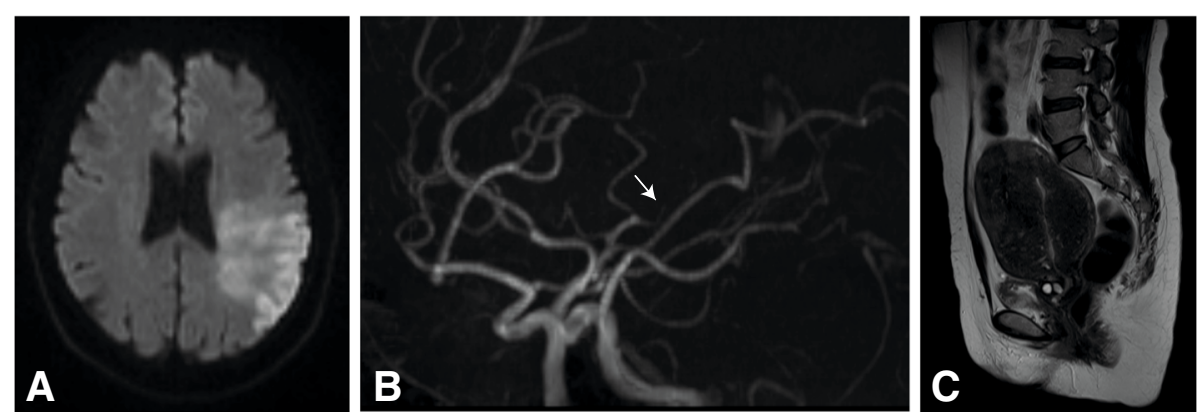

Fig. 1 a Diffusion-weighted magnetic resonance imaging (MRI) revealed an infarct in the left middle cerebral artery territory. b Magnetic resonance angiography showed occlusion at left M2 (arrow). c T2-weighted pelvic MRl revealed enlargement of the uterus and obscure junctional zone, suggesting adenomyosis

left MCA territory. MRA showed occlusion at M1 (Fig. 2a, b). The patient was referred to our hospital for further examination and treatment. On arrival, her NIHSS was 23. Emergent digital subtraction angiography (DSA) was performed and partial reperfusion of the left MCA was found (Fig. 2c). We hesitated to perform endovascular treatment because of the large infarction. After admission, we performed examinations to investigate the cause of cerebral infarction. TTE and TEE showed no remarkable findings, and a 24-h Holter ECG did not show atrial fibrillation or other arrhythmia. DSA and carotid echography did not show atherosclerotic changes at proximal arteries. Blood tests performed to investigate the presence of coagulation disorders (as listed above for case 1) were unremarkable, except for elevation of D-dimer $(3.7 \mu \mathrm{g} / \mathrm{mL})$ and CA125 (143 U/mL; normal, < $35 \mathrm{U} / \mathrm{mL})$. Whole body enhanced CT revealed no malignancy. Pelvic MRI showed uterine adenomyosis (Fig. 2d). Her aphasia gradually improved, but motor aphasia remained.

Based on the above findings, both cases were finally diagnosed with cerebral infarction due to Trousseau syndrome-like hypercoagulability associated with adenomyosis. For secondary prevention, the first patient was treated with warfarin and the second patient was treated with rivaroxaban, and there has been no recurrence for 68 and 19 months and modified rankin scale is 1 and 4 , respectively.

\section{Discussion}

The risk of thrombotic complication is high in patients with malignant tumor, and this condition is referred to as Trousseau syndrome [3]. Varki reported multiple mechanisms of hypercoagulability in patients with malignant tumor, involving tissue factor, mucin, cysteine protease, and various cytokines [4]. Especially, mucin promotes platelet aggregation by interaction with platelet $\mathrm{P}$-selectin and leukocyte L-selectin, with resulting hypercoagulability [5]. CA125 is a repeating peptide epitope of mucin MUC16 and a marker of mucin-producing malignant tumors such as ovarian cancer [6]. Elevation of CA125 in patients with a malignant tumor increases the risk of ischemic stroke [7-9]. Hypercoagulability and elevation of CA125 in patients with adenomyosis has also been reported [1, 2], and as for patients with cancer, hypercoagulability can occur in patients with adenomyosis due to increased expression of tissue factor [2]. Indeed, as shown in Table 1, elevation of D-dimer at onset has been found in all except one of the reported cases of ischemic stroke related to adenomyosis. Elevation of CA125 was also
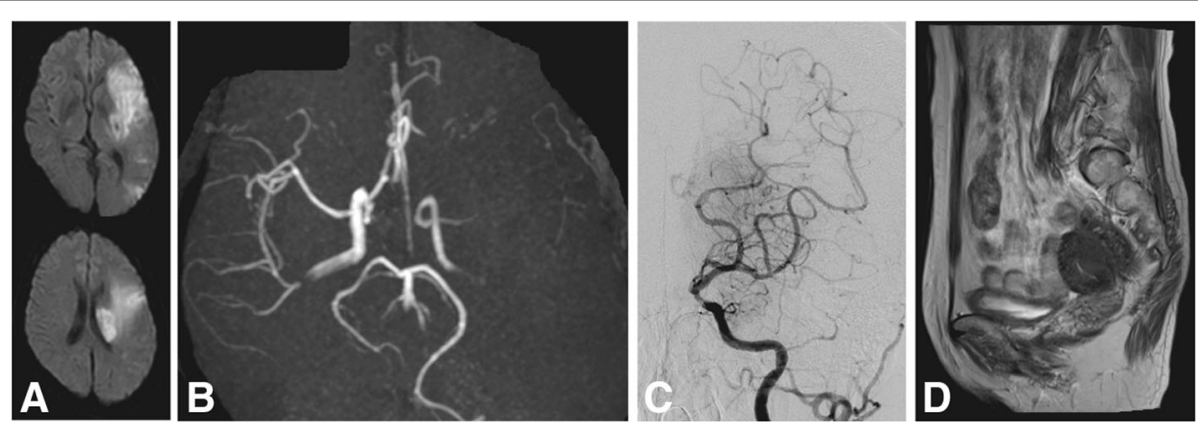

Fig. 2 a Diffusion-weighted MRI revealed an infarct in the left middle cerebral artery territory. b Magnetic resonance angiography at a previous hospital showed left M1 occlusion. c Angiography revealed partial recanalization of the left middle cerebral artery. d Pelvic MRI revealed adenomyosis 
Table 1 Summary of cases of ischemic stroke related to adenomyosis

\begin{tabular}{llllll}
\hline Case No. [Ref] & Age (y.o) & CA125 $(\mathrm{U} / \mathrm{mL})$ & D-dimer $(\mu \mathrm{g} / \mathrm{mL})$ & Secondary prevention & Recurrence \\
\hline $1[9]$ & 45 & 159 & 1.1 & Antiplatelet, GnRH agonist & $(-)$ \\
$2[9]$ & 44 & Not mentioned & FDP $5.9 \mu \mathrm{g} / \mathrm{mL}$ & Warfarin, GnRH agonist & $(-)$ \\
$3[9]$ & 55 & 42.6 & $0.57($ normal) & Aspirin, GnRH agonist & $(-)$ \\
$4[8]^{\text {a }}$ & 42 & 1750 & 6.0 & Antiplatelet $(6 \mathrm{~m})$. GnRH agonist $(6 \mathrm{~m})$ & $(+)$ \\
$5[9]^{\text {a }}$ & 42 & 907 & 4.1 & Warfarin, GnRH agonist & $(-)$ \\
$6[11]$ & 59 & 334.8 & 7.0 & Discontinuation of hormone replacement therapy & $(-)$ \\
$7^{\text {b }}$ & 42 & 395 & 1.4 & Warfarin & $(-)$ \\
$8^{\text {b }}$ & 50 & 143 & 3.7 & Rivaroxaban & $(-)$ \\
\hline
\end{tabular}

${ }^{a}$ Case Nos. 4 and 5 are the same patient

${ }^{b}$ Case Nos. 7 and 8 are the present cases

detected in both of our cases. The previous and current cases indicate that adenomyosis itself seems to cause hypercoagulability through a mechanism similar to that of Trousseau syndrome and may cause ischemic stroke. In contrast to previous reports, both of our patients had large vessel occlusion with emboli and large infarction. As for patients with Trousseau syndrome, both multiple infarction and large vessel occlusion can also occur in patients with mucin-producing adenomyosis and could cause severe neurological deficits, as shown in our cases.

The primary approach to treatment of Trousseau syndrome is to eliminate the causative tumor. This approach could be used for patients with cerebral infarction associated with adenomyosis, but the benign characteristics of the lesion and limited evidence for the cause make it hard to choose surgery as first-line treatment. A gonadotropin-releasing hormone $(\mathrm{GnRH})$ agonist may be a treatment option, based on its effect of decreasing secretion of estrogen. However, side effects restrict the administration period of a $\mathrm{GnRH}$ agonist, and there is a report of a patient (Case No. 4 in Table 1) who had recurrent ischemic stroke after discontinuation of a GnRH agonist $[8,9]$. Antithrombotic drugs are another treatment option. In patients with Trousseau syndrome, heparin, warfarin and other direct oral anticoagulants have been used to prevent thrombosis, although it is still unclear which drug is the most effective [10]. Anticoagulants and antiplatelet agents can also be used in patients with adenomyosis. In our patients, warfarin and rivaroxaban were administered and there have been no recurrent attacks. Long-term hormone replacement therapy may cause hypercoagulability in patients with adenomyosis, and discontinuation of this therapy in one reported case (Case No. 6, Table 1) did not lead to recurrence [11]. Overall, further studies are needed to clarify the mechanisms of development of cerebral infarction in patients with adenomyosis or other mucin-producing benign.

\section{Conclusions}

In conclusion, we have reported two cases of cerebral infarction that seemed to be caused by adenomyosis.
These cases suggest that cerebral infarction might develop in patients with a benign mucin-producing tumor, in addition to cases with a malignant tumor. Cerebral embolism in patients with adenomyosis is not common, but these patients may develop cerebral infarction due to hypercoagulability and elevated CA125. Therefore, we suggest inclusion of adenomyosis as a differential diagnosis in embolic stroke of an undetermined origin in middle-aged women.

\section{Abbreviations}

CT: Computed tomography; DSA: Digital subtraction angiography; DWl: Diffusion-weighted imaging; ECG: Electrocardiogram; GnRH: Gonadotropinreleasing hormone; MCA: Middle cerebral artery; MRI: Magnetic resonance imaging; NIHSS: National Institutes of Health Score Scale; TEE: Transesophageal echocardiography; TTE: Transthoracic echocardiography

Funding

Institutional sources only. No financial support was provided for this study.

\section{Availability of data and materials}

The dataset supporting the conclusion of this article is included within the article.

Authors' contributions

$\mathrm{KO}$ and $\mathrm{FO}$ collected the clinical data and interpreted the data. $\mathrm{HI}$ and MS gave us important clinical opinions. KO drafted the manuscript. FO helped write and revise the manuscript. All authors read and approved the final manuscript.

\section{Ethics approval and consent to participate}

The authors declare that ethics approval was not required for this case report.

\section{Consent for publication}

Written informed consents were obtained from both patients for publication of this case report and accompanying images.

\section{Competing interests}

The authors declare that they have no competing interests.

\section{Publisher's Note}

Springer Nature remains neutral with regard to jurisdictional claims in published maps and institutional affiliations. 
Received: 25 April 2018 Accepted: 28 September 2018

Published online: 04 October 2018

\section{References}

1. Babacan A, Kizilaslan C, Gun I, Muhcu M, Mungen E, Atay V. CA 125 and other tumor markers in uterine leiomyomas and their association with lesion characteristics. Int J Clin Exp Med. 2014;7:1078-83.

2. Liu X, Nie J, Guo SW. Elevated immunoreactivity to tissue factor and its association with dysmenorrhea severity and the amount of menses in adenomyosis. Hum Reprod. 2011;26:337-45.

3. Evans TR, Mansi JL, Bevan DH. Trousseau's syndrome in association with ovarian carcinoma. Cancer. 1996;77:2544-9.

4. Varki A. Trousseau's syndrome: multiple definitions and multiple mechanisms. Blood. 2007;110:1723-9.

5. Wahrenbrock M, Borsig L, Le D, Varki N, Varki A. Selectin-mucin interactions as a probable molecular explanation for the association of trousseau syndrome with mucinous adenocarcinomas. J Clin Invest. 2003:112:853-62.

6. Felder M, Kapur A, Gonzalez-Bosquet J, Horibata S, Heintz J, Albrecht R, et al. MUC16 (CA125): tumor biomarker to cancer therapy, a work in progress. Mol Cancer. 2014;13:129.

7. Jovin TG, Boosupalli V, Zivkovic SA, Wechsler LR, Gebel JM, et al. High titers of CA-125 may be associated with recurrent ischemic strokes in patients with cancer. Neurology. 2005;64:1944-5.

8. Yamashiro K, Furuya T, Noda K, Urabe T, Hattori N, Okuma Y. Cerebral infarction developing in a patient without cancer with a markedly elevated level of mucinous tumor marker. J Stroke Cerebrovasc Dis. 2012;21:619.e1-2.

9. Yamashiro K, Tanaka R, Nishioka K, Ueno Y, Shimura H, Okuma Y, et al. Cerebral infarcts associated with adenomyosis among middle-aged women. J Stroke Cerebrovasc Dis. 2012;21:910.e1-5.

10. Ikushima S, Ono R, Fukuda K, Sakayori M, Awano N, Kondo K. Trousseau's syndrome: cancer-associated thrombosis. Jpn J Clin Oncol. 2016;46:204-8.

11. Hijikata N, Sakamoto Y, Nito C, Matsumoto N, Abe A, Nogami A, et al. Multiple cerebral infarctions in a patient with adenomyosis on hormone replacement therapy: a case report. J Stroke Cerebrovasc Dis. 2016;25:183-4.

Ready to submit your research? Choose BMC and benefit from:

- fast, convenient online submission

- thorough peer review by experienced researchers in your field

- rapid publication on acceptance

- support for research data, including large and complex data types

- gold Open Access which fosters wider collaboration and increased citations

- maximum visibility for your research: over $100 \mathrm{M}$ website views per year

At $\mathrm{BMC}$, research is always in progress.

Learn more biomedcentral.com/submissions 